\title{
Metabolic and cardiovascular risk profiles and hepatitis C virus infection in rural Egypt
}

\author{
D Marzouk, J Sass, I Bakr, M El Hosseiny, M Abdel-Hamid, C Rekacewicz, N Chaturvedi, \\ M K Mohamed, A Fontanet
}

See end of article for authors' affiliations

Correspondence to: Dr Arnaud Fontanet, Emerging Diseases Epidemiology Unit, Institut Pasteur, 28 rue du Docteur Roux, Paris 75015, France; fontanet@pasteur.fr

Revised 10 July 2006

Accepted 15 August 2006

Published Online First

6 September 2006

\begin{abstract}
Background and aim: To investigate the relationship between lipid profiles and diabetes with past and chronic hepatitis $\mathrm{C}$ virus (HCV) infection among village residents of Egypt.

Patients and methods: Fasting lipids and glucose profiles were compared among adults never infected with HCV (negative HCV antibodies), infected in the past (positive HCV antibodies and negative HCV RNA) and chronically infected (positive HCV antibodies and HCV RNA).

Results: Of the 765 participants, 456 (59.6\%) were female, and median age was 40 (range 25-88) years. Chronic HCV infection was present in $113(14.8 \%)$ and past infection in $67(8.8 \%)$. After adjustment for age and sex, participants with chronic HCV infection had lower plasma low density lipoproteins (LDL) cholesterol and triglyceride levels compared with those never infected (age and sex adjusted differences $(95 \% \mathrm{Cl}$ ) were $-19.0(-26.3$ to -11.7$) \mathrm{mg} / \mathrm{dl}$ and $-26.2(-39.0$ to -13.3$) \mathrm{mg} / \mathrm{dl}$, respectively). In contrast, participants with cleared HCV infection had higher triglyceride levels compared with those never infected (age and sex adjusted difference $(95 \% \mathrm{Cl})$ was $+16.0(0.03$ to 31.9$) \mathrm{mg} / \mathrm{dl})$. In multivariate analysis, participants with chronic HCV infection were more likely to have diabetes (OR 3.05, 95\% $\mathrm{Cl} 1.19$ to 7.81 ) compared with those never infected, independent of LDL cholesterol levels.

Conclusion: In conclusion, this community based study has shown that in a single population, chronic HCV infection is associated with glucose intolerance and, despite that, a favourable lipid pattern. An intriguing finding was the high triglyceride levels observed among participants with past infection, suggesting that elevated triglycerides at the time of acute infection may facilitate viral clearance.
\end{abstract}

nfection with hepatitis $\mathrm{C}$ virus (HCV) has been associated with alterations in lipid metabolism in some studies ${ }^{1-3}$ and type 2 diabetes in others. ${ }^{4-8}$ Lipid changes are characterised by hypobetalipoproteinaemia, and may be more common among patients infected with HCV genotype 3 who develop liver steatosis. ${ }^{1-3}$ Type 2 diabetes was initially documented among patients with HCV related cirrhosis, ${ }^{4}$ although subsequent studies have demonstrated its occurrence at all stages of HCV infection. ${ }^{5-8}$ This combination of favourable lipids and diabetes is unusual, as the conventional metabolic syndrome, a constellation of risk factors for atherosclerosis, includes, among others, an atherogenic lipid profile, glucose intolerance and insulin resistance. ${ }^{9}$ Whether the protective effect of hypobetalipoproteinaemia will counterbalance the effect of diabetes in the pathogenesis of atherosclerosis among HCV infected individuals is not known.

Egypt has the highest HCV prevalence in the world (overall prevalence of HCV antibody is $12 \%$ among the general population and reaches $40 \%$ in persons 40 years of age and above in rural areas). ${ }^{10-12}$ The origin of the HCV epidemic in Egypt has been attributed to intravenous schistosomiasis treatment in rural areas in the 1960s-70s. ${ }^{13}$ As treatment was targeted at children and young adults, those infected at that time are now 40-65 years old and will be at risk of cardiovascular disease. We therefore investigated the association between HCV infection and atherosclerosis risk factors in one rural area of Egypt subjected to schistosomiasis treatment campaigns in the past.

\section{SUBJECTS AND METHODS}

The study took place at Zwyat Razin village in the lower Nile Delta region of Egypt. Between March and November 2002, all residents over 5 years of age and living in one sector of the village (representing $25 \%$ of the total village population) were invited to participate in a cohort study of the incidence and progression of HCV infection. ${ }^{14}{ }^{15}$ After informed consent was obtained (from the head of household for children less than 18 years of age), participants were administered a questionnaire on sociodemographic characteristics, clinical history and risk factors for HCV infection. The informed consent form was written in Arabic and read to participants who were illiterate. In each study team, there was a medical doctor able to provide answers to queries from study participants regarding the natural history of HCV infection and cardiovascular disease, the importance of the study and the risks associated with participation in the study (blood drawing). Questionnaires were close-ended and administered by trained interviewers. Venous blood $(10 \mathrm{ml})$ was drawn and transported on the same day for centrifugation and freezing of serum $\left(-70^{\circ} \mathrm{C}\right)$ at the National Hepatology and Tropical Medicine Research Institute (NHTMRI) in Cairo. Serological status was determined according to an algorithm validated locally on Egyptian sera ${ }^{16}$ : sera were first tested for HCV antibodies using Innotest HCV Ab IV (Innogenetics, Ghent, Belgium) (lower 95\% CI of specificity reported at $98.1 \%$ during the evaluation of hepatitis $\mathrm{C}$ assays by the Blood Safety and Clinical Technology of the World Health Organisation ${ }^{17}$ ), samples positive for HCV antibodies were tested again using Abbott HCV EIA 3.0 (Abbott Laboratories, Diagnostics Division, Illinois, USA) and those testing positive by the two serological tests were considered positive for HCV antibodies. Samples with discordant results were considered to

Abbreviations: BMI, body mass index; ElA, enzyme immunoassay; HCV, hepatitis $\mathrm{C}$ virus; $\mathrm{HDL}$, high density lipoprotein; LDL, low density lipoprotein; NHTMRI, National Hepatology and Tropical Medicine Research Institute; VLDL, very low density lipoprotein; WHR, waist hip ratio 
Table 1 Descriptive characteristics of the study population according to sex, Zwyat Razin, 2003

\begin{tabular}{|c|c|c|}
\hline & Males $(n=309)$ & Females $(n=456)$ \\
\hline \multicolumn{3}{|l|}{ Descriptive characteristics (n (\%)) } \\
\hline \multicolumn{3}{|l|}{ Age group (y) } \\
\hline $25-34$ & $93(30.1)$ & $131(28.7)$ \\
\hline $35-44$ & $83(26.9)$ & $138(30.3)$ \\
\hline $45-54$ & $61(19.7)$ & $95(20.8)$ \\
\hline $55-64$ & 34 (11.0) & 60 (13.2) \\
\hline$\geqslant 65$ & $38(12.3)$ & $32(7.0)$ \\
\hline \multicolumn{3}{|l|}{$\mathrm{HCV}$ infection status } \\
\hline Never infected & $224(72.5)$ & $361(79.2)$ \\
\hline Past infection & $22(7.1)$ & $45(9.9)$ \\
\hline Chronic infection & $63(20.4)$ & $50(11.0)$ \\
\hline \multicolumn{3}{|l|}{ Clinical examination (mean (SD)) } \\
\hline Height $(\mathrm{cm})$ & $167.9(7.0)$ & $155.1(6.4)$ \\
\hline Weight (kg) & 72.5 (13.8) & 69.7 (15.9) \\
\hline$B M I\left(\mathrm{~kg} / \mathrm{m}^{2}\right)$ & $25.7(4.5)$ & $28.9(6.3)$ \\
\hline Waist circumference $(\mathrm{cm})$ & $86.5(12.3)$ & $90.3(14.6)$ \\
\hline WHR & $0.90(0.08)$ & $0.88(0.08)$ \\
\hline $\mathrm{SBP}(\mathrm{mm} \mathrm{Hg})$ & $124.6(19.8)$ & $124.6(22.5)$ \\
\hline $\mathrm{DBP}(\mathrm{mm} \mathrm{Hg})$ & $80.7(10.7)$ & $80.6(12.3)$ \\
\hline \multicolumn{3}{|l|}{ Metabolic variables (mean (SD)) } \\
\hline Fasting glucose $(\mathrm{mg} / \mathrm{dl})$ & $85.5(22.5)$ & $88.3(33.0)$ \\
\hline Total cholesterol (mg/dl) & $171.6(37.8)$ & $183.8(41.0)$ \\
\hline LDL cholesterol (mg/dl) & $104.2(34.7)$ & $110.4(37.4)$ \\
\hline $\mathrm{HDL}$ cholesterol (mg/dl) & $42.8(9.0)$ & $50.0(11.6)$ \\
\hline Triglycerides (mg/dl) & $123.4(62.6)$ & 117.5 (64.9) \\
\hline \multicolumn{3}{|l|}{ Current treatments (n (\%)) } \\
\hline Antihypertensive drugs & $24(7.8)$ & $52(11.4)$ \\
\hline Oral antidiabetic drugs & $8(2.6)$ & $16(3.5)$ \\
\hline Insulin & $3(1.0)$ & $3(0.7)$ \\
\hline Cholesterol lowering drugs & $1(0.3)$ & $3(0.7)$ \\
\hline
\end{tabular}

be negative. All HCV antibody positive samples were tested for HCV-RNA using a one step reverse transcriptase-PCR assay (in house assay using $5^{\prime}$ UTR primers with modifications ${ }^{18}$ ) and for serum alanine aminotransferase. Participants with positive HCV-RNA and elevated alanine aminotransferase were invited to attend the study clinic at Ismail Sallam Hospital for treatment with pegylated interferon and ribavirin. The study protocol was approved by the Egyptian Ministry of Health and Population Institutional Review Board and a local ethics committee set up for hepatitis studies in Egypt.

Between June 2003 and March 2004, all participants 25 years of age and above who were willing to be examined for cardiovascular risk factors were invited for this study. A pretested risk factor questionnaire, administered during home visits by trained village social workers, was used to collect

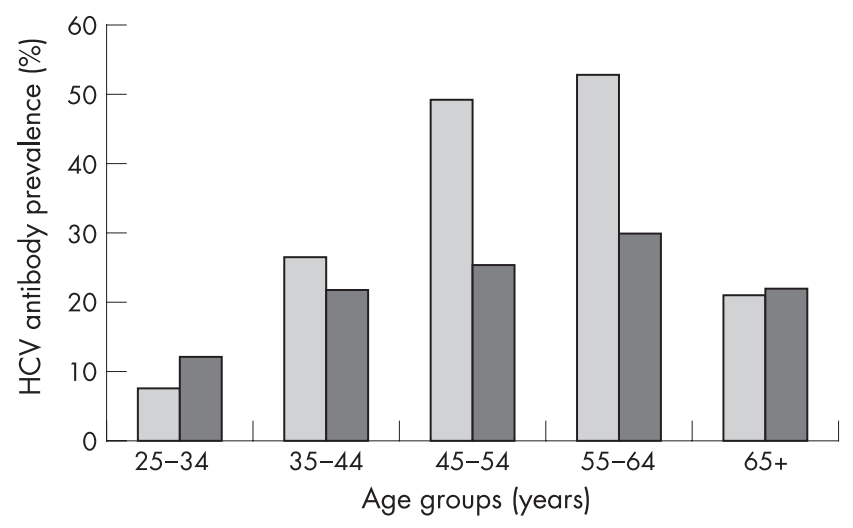

Figure 1 Hepatitis $\mathrm{C}$ virus (HCV) antibody prevalence by age and sex, Zwyat Razin, 2003 (light grey, males; dark grey, females). sociodemographic data (age, sex, education, occupation, etc), personal medical history (eg, past diagnosis of diabetes, hypertension, hypercholesterolaemia, cardiovascular disease, cerebrovascular accidents), family history (diabetes, hypertension, cardiovascular disease, cerebrovascular accidents) and cardiovascular risk factors (smoking history, intake of salty food, physical activity).

Subjects were then invited to come to the study clinic after a $12 \mathrm{~h}$ fasting period for clinical examination and blood sampling. Clinical examinations were performed by a trained physician and included the collection of anthropometric measurements such as weight, height, and waist and hip circumferences. Weight and height were measured using a regularly titrated spring balance and stadiometer, respectively. Waist circumference was measured at the level of the umbilicus. Hip circumference was measured at the most protruding part of the buttocks. Blood pressure was measured at two intervals by a physician using a regularly titrated mercury sphygmomanometer with the subject in a seated position and the arm supported by the table at heart level. If the difference between the first two readings was $\geqslant 10 \mathrm{~mm} \mathrm{Hg}$, a third reading was taken. The average of the first two readings was used for analysis, unless the difference between these readings was $>10 \mathrm{mmHg}$, in which case the mean of the two closest of the three measurements was used. Venous blood samples $(10 \mathrm{ml})$ were taken on gel and centrifuged, and then sent to the NHTMRI Laboratory in Cairo for analysis. An aliquot of serum was stored at $-80^{\circ} \mathrm{C}$ and archived. Blood samples were analysed to determine levels of total cholesterol, triglycerides, high density lipoproteins (HDL), low density lipoproteins (LDL) and blood glucose (Synchron CX4 System; Beckman, USA). Participants diagnosed with diabetes or hypertension were referred to the local health office in the village for followup and treatment. 
Table 2 Atherosclerosis risk factors among individuals with no hepatitis $C$ virus infection, past infection or chronic infection, Zwyat Razin, 2003

\begin{tabular}{|c|c|c|c|c|c|}
\hline & $\begin{array}{l}\text { Never HCV } \\
\text { infected }(n=585)\end{array}$ & $\begin{array}{l}\text { Past HCV } \\
\text { infection }(n=67)\end{array}$ & $\begin{array}{l}\text { Chronic HCV } \\
\text { infection }(n=113)\end{array}$ & $\begin{array}{l}\text { Adjusted }{ }^{*} \text { difference } \\
\text { of past vs never } \\
\text { infected }\end{array}$ & $\begin{array}{l}\text { Adjusted }{ }^{*} \text { difference } \\
\text { of chronic vs never } \\
\text { infected }\end{array}$ \\
\hline BMI $\left(\mathrm{kg} / \mathrm{m}^{2}\right)$ & $27.5(5.91)$ & $28.9(5.49)$ & $27.4(5.75)$ & $0.99(-0.42$ to 2.40$)$ & $0.09(-1.06$ to 1.24$)$ \\
\hline WHR & $0.88(0.08)$ & $0.90(0.07)$ & $0.91(0.09)$ & $0.01(-0.01$ to 0.03$)$ & $0.02(0.001$ to 0.03$) \dagger$ \\
\hline $\mathrm{SBP}(\mathrm{mm} \mathrm{Hg})$ & $124.2(20.4)$ & $128.0(26.8)$ & $125.2(22.9)$ & $0.75(-4.06$ to 0.76$)$ & $-3.71(-7.62$ to 0.20$)$ \\
\hline $\mathrm{DBP}(\mathrm{mm} \mathrm{Hg})$ & $80.4(11.4)$ & $82.1(13.6)$ & $81.2(12.1)$ & $0.36(-2.36$ to 3.08$)$ & $-1.34(-3.56$ to 0.87$)$ \\
\hline Fasting glucose (mg/dl) & $85.6(25.4)$ & $91.3(32.5)$ & $92.7(42.4)$ & $3.45(-3.76$ to 10.7$)$ & $4.71(-1.17$ to 10.59$)$ \\
\hline Total cholesterol (mg/dl) & $181.2(40.6)$ & $189.2(38.4)$ & $160.4(33.1)$ & $4.75(-4.98$ to 14.5$)$ & $-22.9(-30.8$ to -15.0$) \dagger$ \\
\hline LDL cholesterol (mg/dl) & $109.9(36.8)$ & $114.5(36.3)$ & $93.4(30.9)$ & $2.07(-6.90$ to 11.0$)$ & $-19.0(-26.3$ to -11.7$) \dagger$ \\
\hline HDL cholesterol (mg/dl) & $47.2(11.1)$ & $46.7(10.5)$ & 46.7 (12.1) & $-0.59(-3.30$ to 2.10$)$ & $1.24(-0.96$ to 3.43$)$ \\
\hline Triglycerides (mg/dl) & $121.0(66.2)$ & $140.3(65.0)$ & $101.9(45.1)$ & $16.0(0.03$ to 31.9$) \dagger$ & $-26.2(-39.0$ to -13.3$) \dagger$ \\
\hline
\end{tabular}

BMI, body mass index; DBP, diastolic blood pressure; HCV, hepatitis C virus; HDL, high density lipoprotein; LDL, low density lipoprotein; SBP, systolic blood pressure; WHR, waist hip ratio.

*Adjusted for age and sex in a linear regression model.

†Significant $(p<0.05)$ differences are shown in bold typeface.

Values are mean (SD) or $\beta$ coeff $(95 \% \mathrm{Cl})$.

\section{Definitions}

Body mass index (BMI) was calculated as weight in $\mathrm{kg} / \mathrm{height}$ in $\mathrm{m}^{2}$. Android fat distribution and central obesity was measured by calculating the waist-hip ratio (WHR). WHR was obtained by dividing the waist circumference by the hip circumference. Hypertension was defined according to the guidelines of the Joint National Committee on Detection, Evaluation, and Treatment of High Blood Pressure, which are: a systolic blood pressure $\geqslant 140 \mathrm{~mm} \mathrm{Hg}$, a diastolic blood pressure $\geqslant 90 \mathrm{~mm} \mathrm{Hg}$ or the use of antihypertensive medication $(\mathrm{n}=76)$. Subjects in the $130-139 / 80-89 \mathrm{~mm}$ Hg blood pressure range were classified as "pre-hypertensive" (ie, at an increased risk for progression to hypertension). ${ }^{19}$ Persons were considered to have diabetes if they used insulin $(\mathrm{n}=6)$ or oral hypoglycaemic agents $(n=24)$ at the time of the survey or had a fasting plasma glucose level of $126 \mathrm{mg} / \mathrm{dl}$ or more..$^{20}$ Participants with no HCV antibodies were considered as never HCV infected. Those with HCV antibodies, but no HCV RNA, were considered as past HCV infection. Those with HCV antibodies and HCV RNA were considered as chronic HCV infection.

\section{Statistical analysis}

From May to November 2002, 820 houses, containing 1178 families, 5813 inhabitants, with 5130 inhabitants 5 years of age or above, were visited for enrolment in the cohort study of the incidence and progression of HCV infection. Of the 5130 eligible individuals, 4054 (79.0\%) were present at the time of the survey and agreed to participate. Of these, 1873 were 25 years of age or above in 2003 and eligible for the cross sectional survey on cardiovascular risk factors. The latter survey took place between June 2003 and March 2004 and included participants who could be found at the time of the survey: 1523 (81.3\%) subjects completed the questionnaire on cardiovascular risk factors and $779(41.6 \%)$ underwent clinical and laboratory examinations. Compared with non-participating subjects, those with complete data in the cross sectional survey were older (median age of 40 vs 35 years, respectively; $\mathrm{p}<0.001$ ), were more likely female ( $58.7 \%$ vs $44.3 \%$, respectively; $p<0.001$ ) but were not different in terms of HCV infection status (never infected $75.1 \%$ vs $79.5 \%$, respectively; those with past infection, $8.6 \%$ vs $7.5 \%$, respectively; and those with chronic infection $16.3 \%$ vs $13.0 \%$, respectively; $\mathrm{p}>0.05$ ). Fourteen patients with chronic infection had already started antiviral therapy at the time of the second survey and were therefore excluded from further analysis. The analysis focused on the 765 individuals with complete data.
Comparisons of continuous variables between two groups were made using the Student's t test or the Mann-Whitney U test where appropriate. When the comparison of means involved adjustment for age and sex, linear regression was used. The $\chi^{2}$ test and Fisher's exact test were used for categorical data. Multivariate logistic regression was performed to determine factors associated with diabetes. Known risk factors for diabetes were considered for the model, as well as other variables such as the patient's history, clinical or metabolic characteristics. Variables with p values $<0.25$ in univariate analysis were tested together in the logistic regression model, and variables were removed following a backward stepwise selection procedure until all variables left in the model had $\mathrm{p}$ values $<0.05$. All calculations were performed using Stata statistical software (Stata 8.0; Stata Corporation, College Station, Texas, USA).

\section{RESULTS}

Table 1 shows the main characteristics of the 765 study participants: females comprised $59.6 \%$ of the population, median age was 40 (range $25-88$ ) years and $72.5 \%$ of the study participants were illiterate. Chronic and past HCV infections were found in $14.8 \%$ and $8.8 \%$ of the participants, respectively, with a peak in HCV antibody prevalence in the 55-64 year age group (fig 1). Males were taller, heavier, but had a lower BMI and a smaller waist circumference than females. There was no difference in mean systolic or diastolic blood pressure between males and females. Females showed higher total cholesterol, LDL and HDL but lower (marginally significant) triglyceride levels.

BMI, WHR, blood pressure, and glucose and lipid concentrations were compared among participants who had never been infected with HCV, those with past infection and those with chronic infection (table 2). As many of these variables were heavily influenced by age and sex, differences among groups were adjusted for age and sex in a linear regression model. While values were similar between never infected participants and those with past infection (except for higher triglycerides in the latter group), marked differences, such as lower levels of total and LDL cholesterol, lower triglycerides and higher WHR were observed in participants with chronic infection compared with those never infected. Figure 2 shows triglycerides levels by age groups $(<45$ and $\geqslant 45$ years $)$, sex and HCV infection categories. In all four age and sex groups displayed, chronically infected subjects had lower triglycerides levels compared with never infected or past infections. Higher triglycerides levels 


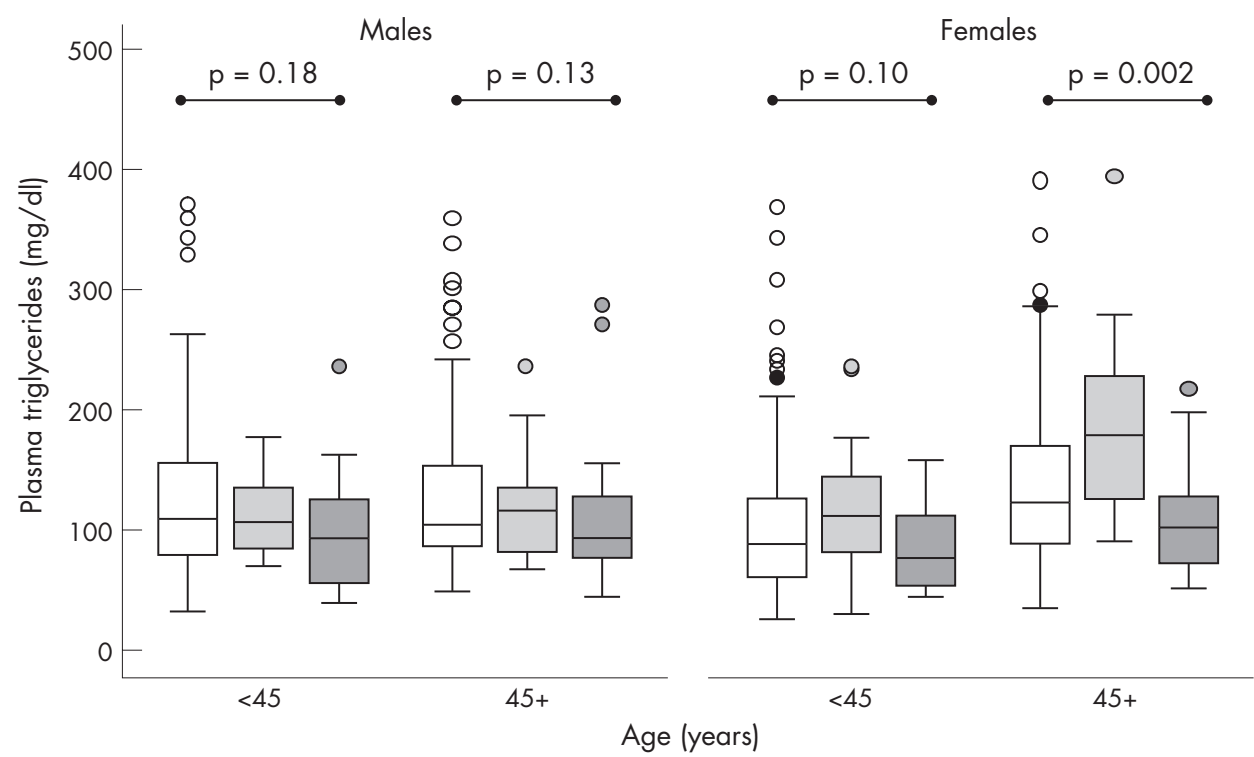

Figure 2 Triglycerides levels by sex, age categories ( $<$ or $\geqslant 45$ years) and hepatitis $C$ virus infection status: never infected (open); past infections (light grey); and chronically infected (dark grey).

were observed in subjects with past infections compared with those never infected (table 2), and this was particularly visible among women 45 years of age and older (fig 2).

Diabetes was present in $41 / 754(5.4 \%)$ of the study population. Of these, $28(68.3 \%)$ were receiving treatment: 22 with oral hypoglycaemics, four with insulin and two with both. In univariate analysis, there was an association between HCV infection status and diabetes: the proportion with diabetes was $25 / 577(4.3 \%)$ among the never infected, $7 / 66$ (10.6\%) among those with past HCV infection and 9/111 (8.1\%) among those with chronic HCV infection $(p=0.04)$. The median (interquartile range) age of those with diabetes was 54 (46-60) years. There was no difference in the median age of patients with diabetes across the three HCV infection categories (54, 52 and 59 years for those never infected, with past infection and chronically infected, respectively; $\mathrm{p}=0.50$ ). Univariate $\mathrm{OR}$ (95\% CI) values of the association with diabetes were 2.62 (1.09-6.32) and $1.95(0.88-4.30)$ for past infection and chronic infection, respectively, when compared with never infected. Adjustment for the factors retained in the final multivariate model (age, family history of diabetes, blood pressure and LDL cholesterol level) strengthened these associations, with the

Table 3 Multivariate analysis of factors associated with diabetes, Zwyat Razin, 2003

\begin{tabular}{|c|c|c|}
\hline & OR $(95 \% \mathrm{Cl})$ & p Value \\
\hline Age $^{*}$ & $1.48(1.10$ to 1.98$)$ & 0.009 \\
\hline \multicolumn{3}{|l|}{ Family history of diabetes } \\
\hline No & 1 & 0.001 \\
\hline Yes & $3.56(1.68$ to 7.52$)$ & \\
\hline \multicolumn{3}{|l|}{ Systolic blood pressure } \\
\hline Normal & 1 & 0.004 \\
\hline Prehypertensive $†$ & $1.65(0.46$ to 6.88$)$ & \\
\hline Hypertensive† & 5.30 (1.67 to 16.8$)$ & \\
\hline \multicolumn{3}{|l|}{$\mathrm{LDL}(\mathrm{mg} / \mathrm{dl})$} \\
\hline$<80$ (low) & $0.62(0.18$ to 2.06$)$ & 0.003 \\
\hline 80-129 (normal) & 1 & \\
\hline$\geqslant 130$ (borderline and high) & $3.16(1.45$ to 6.88$)$ & \\
\hline \multicolumn{3}{|l|}{$\mathrm{HCV}$ infection status } \\
\hline Never infected & 1 & 0.01 \\
\hline Past infection & $3.18(1.21$ to 8.41$)$ & \\
\hline Chronic infection & 3.05 (1.19 to 7.81$)$ & \\
\hline
\end{tabular}

$\mathrm{HCV}$, hepatitis $\mathrm{C}$ virus; $L D L$, low density lipoprotein.

${ }^{*} O R$ for an increase of 10 years of age.

†See section on Definitions in Subjects and methods. adjusted OR (95\% CI) being 3.18 (1.21-8.41) and 3.05 (1.197.81 ), respectively (see table 3 ). Of interest, as shown by the multivariate analysis, the association between HCV infection status and diabetes was independent of LDL cholesterol levels.

\section{DISCUSSION}

HCV antibody prevalence was extremely high in this population of rural Egypt, reaching 50\% and 30\% in males and females aged 55-64 years. Similarly high values have been observed in other rural settings of Egypt, ${ }^{10-12}$ in relation to the spread of HCV by the use of unsterile intravenous injections for the treatment of schistosomiasis in the 1960s-70s. ${ }^{13}$ This unique epidemiological context allowed us to study the relation between cardiovascular risk factors and HCV infection through a community based study, avoiding selection biases associated with hospital based cohorts. While most of the published work has focused on the relations between HCV infection and lipids ${ }^{1-3}$ or diabetes ${ }^{4-8}$ in separate populations, we have addressed these in addition to other factors simultaneously in the same study population. We have also differentiated between study subjects according to whether they had never been infected, they had been infected in the past but cleared the virus or they were chronically infected.

This study shows that in a single population, chronic HCV infection is associated with glucose intolerance and, despite that, a favourable lipid pattern, consisting of an elevation in HDL cholesterol, and a reduction in total cholesterol, LDL cholesterol and triglycerides. The mechanisms of hypobetalipoproteinaemia in chronic HCV infection are still speculative, and may include, among others, the binding of HCV particles to HDL, LDL and very low density lipoprotein (VLDL) ${ }^{22-24}$; the impaired hepatocytic assembly of VLDL through inhibition of the microsomal transfer protein ${ }^{25}$; and the entry of $\mathrm{HCV}$ into hepatocytes through the LDL receptor. ${ }^{26}{ }^{27}$ Hypobetalipoproteinaemia in HCV infection is more common among patients with hepatic steatosis, ${ }^{13}$ a condition possibly related to triglyceride accumulation caused by impaired microsomal transfer protein. ${ }^{25}$ The prevalence of hepatic steatosis is higher among patients infected with HCV genotype 3 compared with other genotypes $(74.1 \%$ vs $47.9 \%$, respectively). ${ }^{28}{ }^{29}$ In patients with genotype 3, viral load has been found to be associated with steatosis whereas in patients with other genotypes, metabolic causes, as reflected by the BMI, are associated with steatosis. ${ }^{30}$ In this study, genotype 4 was the 
most common genotype ( 131 of 133 HCV strains genotyped at the cohort site), and the prevalence of steatosis among patients treated for chronic hepatitis C was 27/54 (=50.0\%) (MKM, personal communication), in line with findings from the literature for patients infected with genotype $4 .^{29}$ The respective role of viral and metabolic causes in determining hypolipoproteinaemia can be explored further by comparing changes in cholesterol levels in responders and non-responders to treatment. Unfortunately, we do not have post-treatment data in this group.

The greater prevalence of diabetes, in those with chronic infection, is thought to be largely because of hepatic insulin resistance although, unlike the classic picture of insulin resistance, this is not accompanied by the typical dyslipidaemic pattern of high triglyceride and low HDL cholesterol levels. In a recent editorial, ${ }^{31}$ Weinman and Belalcazar wondered whether insulin resistance during $\mathrm{HCV}$ infection would result from hepatic steatosis ${ }^{32}$ or from a direct effect of HCV proteins on insulin signalling pathways. ${ }^{33}$ If insulin resistance was the result of hepatic steatosis, we would have seen a higher proportion of diabetes among HCV infected participants with low LDL cholesterol levels, as the latter is correlated with hepatic steatosis. The opposite was observed, providing indirect evidence for a mechanism of insulin resistance independent of hepatic steatosis. The fact that cleared HCV infection was also associated with diabetes suggests that the process leading to diabetes may be initiated early in HCV infection, during the acute phase preceding HCV clearance.

Patients with past infection had similar cholesterol profiles compared with those never infected, suggesting that the differences observed during chronic HCV infection were mediated by viral replication rather than antibodies. A different pattern emerged from the comparison of triglycerides among the three groups of participants: compared with those never infected, those with past infection had higher triglyceride levels and those with chronic infection had lower levels. To our knowledge, this is the first time that a decrease in triglyceride levels has been documented among subjects with chronic HCV infection, in line with previous reports of a rise in triglycerides during interferon therapy for chronic hepatitis. ${ }^{34}$ While the decrease in triglyceride levels in chronic infection could be explained through metabolic processes associated with viral replication, ${ }^{25}$ the increase in triglyceride levels associated with past infections is a challenging finding. A stimulating hypothesis would be that high concentrations of triglycerides at the time of acute infection compete with HCV for binding to the hepatocyte receptors, resulting in lower hepatocyte entry and easier infection clearance among those with high triglyceride levels. Monazahian et al previously suggested that free betalipoproteins in human serum may regulate the rate of infection of liver cells by competing with the virus on putative receptors. ${ }^{27}$ In support of this hypothesis are two in vitro models in which the binding of lipo-viro-particles ${ }^{24}$ or natural $\mathrm{HCV}^{35}$ to human hepatocytes was inhibited by VLDL. As triglyceride levels are not routinely checked in this rural population with limited access to health services, it is conceivable that subjects with high triglyceride levels maintain this status throughout their lifetime in the absence of any dietary or therapeutic intervention. Thus differences in triglyceride levels which might have existed at the time of acute HCV infection would still be observed years after viral clearance, as in this study. Interestingly, the highest HCV clearance rates published so far were among early post-partum women infected with HCV contaminated anti-D immune globulin in Ireland and East Germany (clearance rate of $45 \%$ in both cohorts). ${ }^{36}{ }^{37}$ Whether the two- to three-fold elevation of triglyceride levels associated with the third trimester of pregnancy ${ }^{38}$ contributed to this high clearance rate would be meaningful to consider.
In conclusion, this community based study has shown that in a single population, chronic HCV infection is associated with glucose intolerance and, despite that, a favourable lipid pattern, consisting of an elevation in HDL cholesterol and a reduction in total cholesterol, LDL cholesterol and triglycerides. These associations were independent in the multivariate analysis, in favour of separate metabolic pathways in their occurrence. An intriguing finding was the high triglyceride level observed among subjects with past infection, suggesting that elevated triglycerides at the time of acute infection may facilitate viral clearance. The long term follow-up of this population will reveal whether HCV infected subjects have a different cardiovascular risk compared with the general population.

\section{ACKNOWLEDGEMENTS}

We would like to thank the nurse and laboratory staff working at the study site for their collaboration; Dr Naglaa Arafa and the data management staff at the Department of Community Medicine, Environmental and Occupational Medicine, Faculty of Medicine, Ain Shams University, for their help in study design and management; Dr Saeed Aoun, from the Ministry of Health and Population, for his continuous support to the project; and the study participants for joining the study.

\section{Authors' affiliations}

D Marzouk, I Bakr, M El Hosseiny, M K Mohamed, Department of Community, Environmental and Occupational Medicine, Faculty of Medicine, Ain Shams University, Cairo, Egypt

J Sass, C Rekacewicz, A Fontanet, Emerging Disease Epidemiology Unit, Institut Pasteur, Paris, France

M Abdel-Hamid, Viral Hepatitis Research Laboratory, National Hepatology and Tropical Medicine Research Institute, Cairo, Egypt N Chaturvedi, National Heart and Lung Institute, Imperial College, London, UK

The study was supported financially by the European Community (INCOMED Programme: Viral Hepatitis Surveillance in Mediterranean Countries, Contract ICA3-CT-2000-30011) and the Agence Nationale de Recherches sur le SIDA, hépatites B et C-France (ANRS 1211).

\section{Conflicts of interest: None}

The study protocol was approved by the Egyptian Ministry of Health and Population Institutional Review Board and a local ethics committee set up for hepatitis studies in Egypt.

\section{REFERENCES}

1 Serfaty L, Andreani T, Giral P, et al. Hepatitis C virus induced hypobetalipoproteinemia: a possible mechanism for steatosis in chronic hepatitis C. J Hepatol $2001 ; 34: 428-34$.

2 Hofer $\mathrm{H}$, Bankl HC, Wrba F, et al. Hepatocellular fat accumulation and low serum cholesterol in patients infected with HCV-3a. Am J Gastroenterol 2002;97:2880-5.

3 Petit JM, Benichou M, Duvillard L, et al. Hepatitis C virus-associated hypobetalipoproteinemia is correlated with plasma viral load, steatosis, and liver fibrosis. Am J Gastroenterol 2003;98:1150-4.

4 Allison ME, Wreghitt T, Palmer CR, et al. Evidence for a link between hepatitis C virus infection and diabetes mellitus in a cirrhotic population. J Hepatol 1994;21:1135-9.

5 Mason AL, Lau JY, Hoang N, et al. Association of diabetes mellitus and chronic hepatitis C virus infection. Hepatology 1999;29:328-33.

6 Mehta SH, Brancati FL, Sulkowski MS, et al. Prevalence of type 2 diabetes mellitus among persons with hepatitis C virus infection in the United States. Ann Intern Med 2000; 133:592-9.

7 Knobler H, Schihmanter R, Zifroni A, et al. Increased risk of type 2 diabetes in noncirrhotic patients with chronic hepatitis $\mathrm{C}$ virus infection. Mayo Clin Proc 2000;75:355-9.

8 Mehta SH, Brancati FL, Strathdee SA, et al. Hepatitis C virus infection and incident type 2 diabetes. Hepatology 2003;38:50-6.

9 Expert Panel on Detection, Evaluation, and Treatment of High Blood Cholesterol in Adults. Exec. Summary of the National Cholesterol Education Program (NCEP) Expert Panel on Detection, Evaluation and Treatment of High Blood Cholesterol in Adults (Adult Treatment Panel III). JAMA 2001;285:2486-97.

10 Habib M, Mohamed MK, Abdel-Aziz F, et al. Hepatitis $C$ virus infection in a community in the Nile Delta: risk factors for seropositivity. Hepatology $2001 ; 33: 248-53$ 
11 Darwish MA, Faris R, Clemens JD, et al. High seroprevalence of hepatitis A, B, C and $E$ viruses in residents in an Egyptian village in the Nile Delta: a pilot study. Am J Trop Med Hyg 1996;54:554-8.

12 Medhat A, Shehata M, Magder S, et al. Hepatitis $C$ in a community in Upper Egypt: Risk factors for infection. Am J Trop Med Hyg 2002;66:633-8.

13 Frank C, Mohamed MK, Strickland GT, et al. The role of parenteral antischistosomal therapy in the spread of hepatitis $C$ virus in Egypt. Lancet 2000;355:887-91.

14 Arafa N, El Hoseiny M, Rekacewicz C, et al. Changing pattern of HCV spread in rural areas of Egypt. J Hepatol 2005;43:418-24.

15 Schwarzinger M, Dewedar S, Rekacewicz C, et al. Chronic hepatitis C virus infection: does it really impact health-related quality of life? A study in rural Egypt. Hepatology 2004;40:1434-41.

16 Abdel-Hamid M, El-Daly M, El-Kafrawy S, et al. Comparison of second- and third-generation enzyme immunoassays for detecting antibodies to hepatitis $C$ virus. J Clin Microbiol 2002;40:1656-9

17 WHO. Blood Safety and Clinical Technology. Hepatitis $C$ assays: operational characteristics (Phase 1), Report 2.Geneva:World Health Organisation, July 2001.http://www.who.int/diagnostics_laboratory/evaluations/en/ hcv_rep2.pdf (accessed 2 May 2007).

18 Abdel-Hamid M, Edelman DC, Highsmith WE, et al. Optimization, assessment, and proposed use of a direct nested reverse transcription-polymerase chain reaction protocol for the detection of hepatitis C virus. J Hum Virol 1997;1:58-65.

19 Chobanian AV, Bakris GL, Black HR, et al. National Heart, Lung, and Blood Institute Joint National Committee on Prevention, Detection, Evaluation, and Treatment of High Blood Pressure; National High Blood Pressure Education Program Coordinating Committee. The seventh report of the Joint National Committee on Detection, Evaluation, and Treatment of High Blood Pressure: the JNC 7 report. JAMA 2003;289:2560-72.

20 Alberti KG, Zimmet PZ. Definition, diagnosis and classification of diabetes mellitus and its complications. Part 1: diagnosis and classification of diabetes mellitus provisional report of a WHO consultation. Diabet Med 1998;15:539-53.

21 Prior MJ, Prout T, Miller D, et al. C-peptide and classification of diabetes mellitus patients in Early Treatment Diabetic Retinopathy Study. Report number 6. The EDTRS Research Group. Ann Epidemiol 1993;3:9-17.

22 Thomssen $R$, Bonk S, Thiele A. Density heterogeneities of hepatitis $C$ virus in human sera due to the binding of B-lipoproteins and immunoglobulins. Med Microbiol Immunol 1993;182:329-34.

23 Monazahian M, Kippenberger S, Muller A, et al. Binding of human lipoproteins (low, very low, high density lipoproteins) to recombinant envelope proteins of hepatitis C virus. Med Microbiol Immunol 2000;188:177-84.
24 André $\mathbf{P}$, Komurian-Pradel F, Deforges S, et al. Characterization of low- and very-low-density hepatitis $C$ virus RNA-containing particles. J Virol 2002;76:6919-28.

25 Perlemuter G, Sabile A, Letteron $P$, et al. Hepatitis $C$ virus core protein inhibits microsomal triglyceride transfer protein activity and very low density lipoprotein secreation: a model of viral-related steatosis. FASEB J 2002;16:185-94.

26 Agnello V, Abel G, Elfahal $M$, et al. Hepatitis $C$ virus and other Flaviviridae viruses enter cells via low density lipoprotein receptor. Proc Natl Acad Sci USA 1999:96:12766-71.

27 Monazahian M, Böhme I, Bonk S, et al. Low density lipoprotein receptor as a candidate receptor for hepatitis C virus. J Med Virol 1999;57:223-9.

28 Mihm S, Fayyazi A, Hartmann $\mathrm{H}$, et al. Analysis of histopathological manifestations of chronic hepatitis $C$ virus infection with respect to virus genotype. Hepatology 1997;25:735-9.

29 Leandro G, Mangia A, Hui J, et al. Relationship between steatosis, inflammation, and fibrosis in chronic hepatitis C: a meta-analysis of individual patient data. Gastroenterology 2006;130:1636-42.

30 Lonardo A, Loria $\mathrm{P}$, Adinolfi LE, et al. Hepatitis $\mathrm{C}$ and steatosis: a reappraisal. $J$ Viral Hepatitis 2006;13:73-80.

31 Weinman SA, Belalcazar LM. Hepatitis C: a metabolic liver disease. Gastroenterology 2004;126:917-19.

32 Kim JK, Fillmore JJ, Chen Y, et al. Tissue-specific overexpression of lipoprotein lipase causes tissue-specific insulin resistance. Proc Natl Acad Sci USA $2001 ; 98: 7522-7$

33 Shintani $Y$, Fujie $H$, Miyoshi $H$, et al. Hepatitis $C$ virus infection and diabetes: direct involvement of the virus in the development of insulin resistance. Gastroenterology 2004; 126:840-8.

34 Naeem M, Bacon BR, Mistry B, et al. Changes in serum lipoprotein during interferon therapy in chronic hepatitis. Am J Gastroenterol 2001;96:2468-72.

35 Maillard P, Huby T, Andreo $U$, et al. The interaction of natural hepatitis $C$ virus with human scavenger receptor SR-BI/Clal is mediated by ApoB-containing lipoproteins. FASEB J 2006;20:735-7.

36 Kenny-Walsh E for the Irish Hepatology Research Group. Clinical outcomes after hepatitis $C$ infection from contaminated anti-D immune globulin. N Engl J Med 1999;340:1228-33.

37 Wiese M, Berr F, Lafrenz M, et al. Low frequency of cirrhosis in a hepatitis $C$ (genotype 1b) single-source outbreak in Germany: a 20-year multicenter study. Hepatology 2000;32:91-6.

38 Piechota W, Staszewski A. Reference ranges of lipids and apolipoproteins in pregnancy. Eur J Obstet Gynecol Reprod Biol 1992;45:27-35. 